\title{
Experimental approaches for the generation of induced pluripotent stem cells
}

\author{
Cesar A Sommer and Gustavo Mostoslavsky*
}

\begin{abstract}
Derivation of autologous induced pluripotent stem cells (iPSCs) through direct reprogramming of easily accessible somatic cells holds the potential to transform the field of regenerative medicine. Since Takahashi and Yamanaka's groundbreaking study describing the generation of iPSCs by retroviralmediated delivery of defined transcription factors, substantial progress has been made to improve both the efficiency and safety of the method. These advances have provided new insights into the molecular mechanisms of reprogramming and promise to accelerate the clinical translation of iPSC technology. Here, we summarize current reprogramming methodologies with a focus on the production of transgene-free or genetically unmanipulated iPSCs and highlight important technical details that ultimately may influence the biological properties of pluripotent stem cells.
\end{abstract}

\section{Introduction}

The potential use of embryonic stem cells (ESCs) for cell replacement therapies is limited by ethical concerns and the technical hurdles associated with their isolation from human embryos. In addition, as the genetic identity of the donor egg from which the ESCs are derived most likely will differ from that of potential recipients, patients who receive ESC-derived cells or tissues may face the same complications that result from organ transplantation (for example, immunorejection, graft-versus-host disease, and need for immunosuppression). To circumvent these obstacles, considerable effort has been invested in attempting to derive ESC-like cells by reprogramming somatic cells to an embryonic state. Although exciting results have been achieved by means

*Correspondence: gmostosl@bu.edu

Section of Gastroenterology, Department of Medicine and Center for Regenerative Medicine (CReM), Boston University School of Medicine, Boston, MA 02118, USA of somatic cell nuclear transfer, cell fusion, and cultureinduced reprogramming [1], these procedures are technically demanding and inefficient and therefore unlikely to become a common approach for producing patientspecific pluripotent cells. In 2006, a major breakthrough was reported in Japan by Takahashi and Yamanaka, who described the generation of induced pluripotent stem cells (iPSCs) from mouse fibroblasts via overexpression of defined transcription factors [2]. Shortly afterwards, the original experimental protocol was replicated and optimized by several laboratories, confirming that iPSCs share the gene expression profile, epigenetic modifications, and proliferation rates as well as the pluripotency of ESCs [3]. Importantly, iPSCs were subsequently derived from adult human fibroblasts, providing a feasible way of producing tailor-made pluripotent cells with clinical translational potential [4-7].

The fact that iPSCs can be derived from easily accessible somatic cells, such as skin fibroblasts or keratinocytes [8], has opened up new horizons in the field of regenerative medicine [9]. Jaenisch and colleagues $[10,11]$ showed - as proof of principle of the therapeutic potential of iPSCs - the rescue of sickle cell disease and Parkinson disease in mouse models after transplantation of iPSC-derived hematopoietic stem cells and dopaminergic neurons, respectively. Similarly, correction of a mouse model of hemophilia A was recently demonstrated by intra-liver injection of endothelial cells and endothelial progenitor cells differentiated from iPSCs [12]. On the basis of the unlimited capacity to be propagated in vitro, iPSCs are good targets for genetic manipulation by gene therapy or gene correction by homologous recombination. Ideally, iPSC-based therapies in the future will rely on the isolation of skin fibroblasts or keratinocytes, their reprogramming into iPSCs, and the correction of the genetic defect followed by differentiation into the desired cell type and transplantation. Although this technology holds the potential to revolutionize drug discovery and regenerative medicine, important technical issues associated with the derivation of iPSCs still hinder its clinical translation. In this review, we outline current reprogramming approaches developed to improve the safety and efficiency of the method and highlight its critical 
aspects that may have an impact on the quality of the iPSCs.

\section{Delivery of reprogramming factors by integrating viral vectors}

Several experimental strategies have been developed to derive iPSCs from differentiated somatic cells (summarized in Figure 1). Direct reprogramming was originally achieved by retroviral transduction of transcription factors. Retroviruses are highly efficient gene-transfer vehicles because they provide prolonged expression of the transgene after genomic integration and have low immunogenicity. Most replication-defective retroviral vectors derive from the Moloney murine leukemia virus by replacing the viral structural genes ( $\mathrm{gag}$, pol, and env) with the gene of interest while retaining the cis-acting sequences. These include the $5^{\prime}$ and $3^{\prime}$ ' long terminal repeats (LTRs), a packaging signal, and elements involved in reverse transcription and chromosomal integration. To produce recombinant retroviruses, the plasmid is introduced into a packaging cell line that provides the viral proteins in trans. Using four individual retroviruses encoding the transcription factors Oct4, Klf4, Sox2, and c-Myc, Takahashi and Yamanaka [2] were able to obtain pluripotent cells by selecting for Fbx15 expression in ESC culture conditions. Fbx15, though an ESC marker, is not essential for the maintenance of the pluripotent state, and this, together with the timing of drug selection, may explain why the first iPSC lines failed to generate adult chimeric mice and exhibited a global gene-expression profile that was similar but not identical to that of ESCs. Further studies showed that delayed selection for the expression of key regulators of pluripotency such as Oct4 or Nanog yielded germline-competent iPSCs [13-15]. Importantly, fully reprogrammed clones could also be derived from genetically unmodified cells by means of colony morphology-based selection [16], thus enabling many laboratories to use the technique without requiring specific cell lines. Shortly after the original report by Takahashi and Yamanaka, their group [5] and teams led by James Thomson [6] in Wisconsin and George Daley [4] in Boston were able to produce iPSCs from human fibroblasts by using a similar experimental design. In all cases, the resulting human iPSCs (hiPSCs) were remarkably similar to human ESCs in terms of morphology, surface marker expression, methylation status in the promoter regions of pluripotency-associated genes, in vitro differentiation, and teratoma formation. After these first studies, retroviruses were used to reprogram somatic cells from patients with a variety of diseases, including amyotrophic lateral sclerosis, Parkinson disease, type 1 diabetes mellitus, Huntington disease, and Down syndrome $[17,18]$, providing an unprecedented opportunity for disease modeling and drug screening.
Delivery of reprogramming factors via lentiviral vectors was first reported by the Thomson lab [6] and later was successfully employed to generate hiPSCs from various cell types, including skin fibroblasts, keratinocytes [19], and adipose stem cells [20]. Lentiviruses are a subclass of retroviruses capable of transducing a wide range of both dividing and non-dividing cells. Lentiviral insertion sites are often found anywhere within the transcriptional unit, whereas gamma-retroviruses tend to integrate near transcriptional start sites [21]. Another major difference between retroviral and lentiviral vectors is the degree of silencing to which they are subject in pluripotent cells. For retroviruses, silencing is almost complete and provides a way to identify fully reprogrammed clones [22] but also decreases the efficiency of the process. Lentiviruses seem to escape silencing to varying degrees, depending in part on the species and the promoter sequence. Moreover, position effects are often associated with variegated expression of the transgene. Even with doxicycline-inducible systems, low levels of transgene expression have been found to affect the transcriptome of iPSCs [23]. This adverse effect is more pronounced with constitutive promoters like human EF1 $\alpha$ (elongation factor-1 alpha), whose activity in the context of reprogramming results in continued transgene expression that severely impairs differentiation both in vivo and in vitro [24]. The lack of silencing of lentiviral vectors increases the efficiency of iPSC generation, but transgene excision may be required to generate fully functional pluripotent cells [24].

\section{Excisable vectors for the production of transgene- free induced pluripotent stem cells}

Despite the fact that viral vectors have proven to be effective tools for reprogramming, the resulting iPSC clones usually display several proviral integrations, ultimately increasing the risk of insertional mutagenesis. In addition, spontaneous transgene reactivation may occur and lead to tumor formation [13]. Furthermore, we have shown that residual transgene expression affects the developmental potential of iPSCs [24]. These findings have encouraged researchers to look for alternative genedelivery methods to generate transgene-free iPSCs that are suitable for basic research and clinical applications.

A feasible way to decrease the risk of insertional mutagenesis is to combine the reprogramming factors into a single polycistronic vector by inserting a 'self-cleaving' 2A peptide or an internal ribosome entry site (IRES) sequence between two consecutive open reading frames. With this approach, expression of the four factors can be accomplished in virtually every transduced cell, with a consequent increase in the reprogramming efficiency. A number of studies have recently demonstrated the advantage of using polycistronic vectors for iPSC 


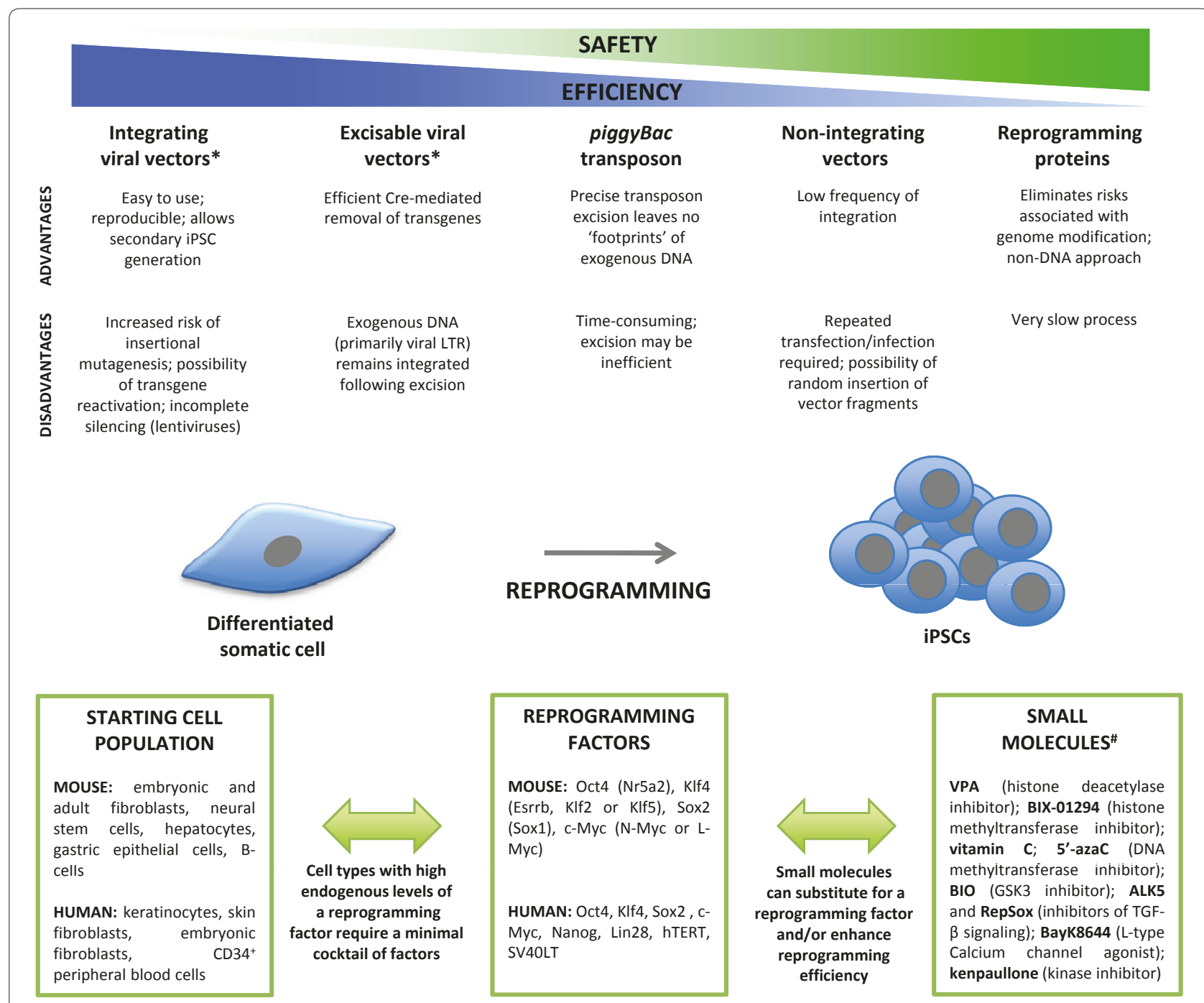

Figure 1. Overview of reprogramming methodologies. *Overall comparable efficiency. "Reprogramming using only small molecules has not been reported yet. 5'-azaC, 5'-azacytidine; iPSC, induced pluripotent stem cell; LTR, long terminal repeat; TGF- $\beta$, transforming growth factor-beta; VPA, valproic acid.

generation. Our group showed efficient conversion of adult mouse fibroblasts to iPSCs $(0.5 \%$ to $1 \%$ of transduced cells) by using either a constitutive or an inducible version of the Stem Cell Cassette (STEMCCA) polycistronic lentiviral vector [25]. In this vector, a combination of $2 \mathrm{~A}$ peptides with an IRES sequence allowed the appropriate expression of the four reprogramming factors. Similarly, the Jaenisch group [26] developed a single polycistronic Dox-inducible lentiviral vector encoding the four factors separated by three different $2 \mathrm{~A}$ peptides and demonstrated successful reprogramming of mouse fibroblasts and neonatal human foreskin keratinocytes with $0.0001 \%$ and $0.00001 \%$ efficiencies, respectively. Notably, these studies demonstrated that somatic cells carrying a single proviral copy of the polycistronic cassette can be reprogrammed to pluripotency, substantially reducing genomic modification of the target cell.

The possibility of deriving iPSCs with single proviral integrations has stimulated the development of methodologies aimed at removing the transgenes by Cre/loxP technology. To this end, a loxP site is inserted into the 3 ' LTR region of the lentiviral vector. During the normal reverse transcription cycle of the virus before integration, the loxP sequence is duplicated into the $5^{\prime}$ LTR region, creating a loxP-flanked or 'floxed' version of the vector that integrates into the host chromosome. After reprogramming, transgene-free iPSCs can be obtained by treatment with Cre recombinase and selection of clones that have undergone excision. Soldner and colleagues [23] performed excision of multiple integrated lentiviral vectors in hiPSCs by transfecting the cells with a plasmid 
co-expressing Cre and the puro gene followed by selection of resistant clones. Similarly, a Cre-expressing plasmid or adenovirus was employed to remove three or four copies of a polycistronic vector from the genome of mouse iPSCs [27]. Moving the technology a step forward, we accomplished highly efficient removal of a single copy of the 'floxed' STEMCCA vector in mouse iPSCs through adenoviral-mediated expression of Cre in the absence of selection [24]. Likewise, efficient excision of a single integrated human STEMCCA vector has been achieved by transfection of a Cre-IRES-Puro plasmid to obtain hiPSCs free of exogenous transgenes (Somers A et al., in press). These approaches, however, do not completely eliminate the theoretical risk of insertional mutagenesis since approximately 200 base pairs of exogenous DNA remain in the host genome after excision. The fact that the remaining sequence is an inactive viral LTR, together with the possibility of sequencing the integration site, may improve the applicability of these approaches in the clinical arena.

As an alternative to integrating viral vectors, the piggyBac (PB) transposon/transposase system has been recently adapted for iPSC generation. PB transposons are characterized by a high transposition activity in mammalian cells and a precise self-excision from genomic loci in mouse ESCs [28]. Woltjen and colleagues [29] engineered a PB transposon-based multiprotein expression vector to generate iPSCs carrying a single genomic integration. Remarkably, as a result of the transient expression of PB transposase, 90\% of the clones showed no traces of exogenous DNA after excision. Yusa and colleagues [30] further optimized the protocol by including a negative selection cassette to facilitate the identification of integration-free iPSCs. This method is significantly less efficient than lentiviral-mediated reprogramming [31] but is substantially safer. Nevertheless, its potential use in a clinical setting will require a thorough examination of the iPSC clones to exclude the presence of transposon-induced genomic rearrangements [32].

\section{Non-integrating vectors and direct delivery of reprogramming proteins}

IPSCs result from the overexpression of transcription factors over several days during which the endogenous factors are activated and maintain the pluripotency gene network [33,34]. In principle, transient expression of the reprogramming factors from non-integrating vectors could provide the level and duration of expression that are required to induce pluripotency. A number of studies have described the successful derivation of mouse iPSCs by using plasmids [35,36] and adenoviral vectors [37], providing proof of principle that proviral insertions are not necessary for iPSC generation. Most recently, expression of reprogramming factors from a non-viral minicircle vector proved capable of converting human adipose stem cells to pluripotency [38]. Likewise, Fusaki and colleagues [39] used RNA Sendai virus-based vectors to achieve reprogramming of human somatic cells and were able to derive transgene-free hiPSCs by antibodymediated negative selection. Alternatively, Thomson and colleagues [40] employed an oriP/EBNA1 episomal vector to reprogram human fibroblasts. Derived from the Epstein-Barr virus, these plasmids replicate extrachromosomally but are gradually lost from cells upon removal of drug selection. The strategy of these authors entailed the introduction of a polycistronic vector encoding the genes Oct4, Sox2, Nanog, Lin28, c-Myc, Klf4, and SV4OLT and selection of stable episomes that provided persistent gene expression to achieve reprogramming followed by the identification of vector-free subclones after several passages in the absence of selection. As with the other non-integrating delivery systems, the reprogramming rates were very low (approximately $0.0005 \%$ ). To date, it remains unclear whether these approaches could be translated to the clinic given the low efficiencies reported. In addition, the possibility that vector pieces have integrated into the host genome is difficult to rule out by polymerase chain reaction analysis and this matter may require whole-genome sequencing [9].

One possible way to induce pluripotency in somatic cells while avoiding the risks of genomic modifications is through direct delivery of reprogramming proteins. Such a strategy has been reported by different groups. To enable cellular uptake, the reprogramming factors were tagged to a poly-arginine protein transduction domain and produced in Escherichia coli. As a result of repeated incubation of mouse fibroblasts with the purified tagged proteins and the histone deacetylase inhibitor valproic acid (VPA), a few iPSC colonies emerged on days 30 to 35 [41]. Kim and colleagues [42] recently extended these findings to produce hiPSCs by means of a slightly different approach, which employed whole-protein extracts from HEK293 cells stably expressing the tagged reprogramming proteins. Finally, a recent report demonstrates that a single transfer of ESC-derived proteins is able to induce pluripotency in adult mouse fibroblasts [43]. Although the generation of these so-called protein hiPSCs (p-hiPSCs) is quite inefficient (about $0.001 \%$ of input cells) and takes about 8 weeks, the study is proof of concept that human somatic cells can be reprogrammed by direct protein delivery. Importantly, p-hiPSCs were produced in the absence of chemicals such as VPA, which may induce mutations [9].

It is widely accepted that the choice of the delivery method will impact the reprogramming efficiency, which is defined as the number of formed colonies divided either by the number of cells seeded or, more accurately, by the number of cells that were effectively transduced/ transfected with the reprogramming factors [44]. 
Interestingly, even at a high multiplicity of infection, the number of colonies that emerge in a typical experiment using retro/lentiviruses is low, and most studies have reported reprogramming rates of $0.001 \%$ to $1 \%$. In fact, the evidence indicates that in addition to the delivery method, these values will be subject to other sources of variation that include the transcription factors and target cell type employed, the age of the donor, the passage number of the cells (inversely correlated with efficiency), and whether the specific protocol includes splitting of cells after infection/transfection. These variables hinder proper comparisons across the studies, even when similar delivery methods are used.

\section{Transcription factor cocktails, donor cells, and chemical additives: the various ways to create an induced pluripotent stem cell}

In their seminal work, Takahashi and Yamanaka [2] screened a library of 24 transcription factors for their ability to induce pluripotency in somatic cells and ultimately selected four (Oct4, Klf4, Sox2, and c-Myc), which are commonly referred to as the 'Yamanaka factors'. Exogenous expression of these genes was found to be effective also in reprogramming human somatic cells, as reported one year later [5]. Concurrently, the Thomson group [6] demonstrated hiPSC derivation by using a slightly different set of transcription factors, namely Oct4, Sox2, Nanog, and Lin28. At present, Oct4 is the only factor that cannot be replaced by other Oct family members [45], and this is consistent with its critical role in maintaining pluripotency [46]. A recent report, however, indicates that Oct4-independent reprogramming is possible through overexpression of the orphan nuclear receptor $\mathrm{Nr} 5 \mathrm{a} 2$ [47], which operates in part by activating endogenous Nanog and Oct4. Interestingly, another orphan nuclear receptor, Esrrb, is capable of replacing Klf4 [48]. Moreover, p53 siRNA (short interfering RNA) and UTF1 were found to significantly increase the efficiency of iPSCs generated with the Yamanaka factors [49]. Not surprisingly, few factors are required to impart pluripotency in cell types that already express high endogenous levels of a reprogramming factor. For example, fibroblasts can be reprogrammed without c-Myc [45] and overexpression of only Oct4 converts neural stem cells into iPSCs [50], albeit at very low rates. Together, these studies provide new insights into the molecular basis of nuclear reprogramming and indicate that different sets of exogenously introduced transcription factors can jump-start the endogenous pluripotency gene network. Whether the choice of the reprogramming cocktail contributes to the variability observed across iPSC lines deserves further investigation.

Nuclear reprogramming to pluripotency is a gradual process that involves the conversion of the epigenetic state of a differentiated cell into that of an ESC-like cell [1]. To date, iPSCs have been produced from several types of somatic cells, including embryonic and adult fibroblasts [2], keratinocytes [8], neural stem cells [51], hepatocytes and gastric epithelial cells [52], B lymphocytes [53], and peripheral blood cells [54]. However, as each mammalian cell type is characterized by a distinct epigenome, some of them appear to be more amenable to reprogramming. Thus, mouse embryonic fibroblasts reprogram more rapidly and efficiently than adult fibroblasts [55], and reprogramming is faster in mouse stomach and liver cells compared with fibroblasts [52]. Similarly, reprogramming appears to be at least 100 -fold more efficient in human keratinocytes than in fibroblasts [8], although this has not been reproduced by others yet [19]. The use of 'reprogrammable' mouse strains could provide further insight into the reprogrammability of different specialized cell types [56]. In fact, a secondary system for the inducible expression of the reprogramming factors was recently employed to analyze the impact of the differentiation status of the cell on reprogramming. By examining the reprogrammability of hematopoietic cells at different stages of development, Eminli and colleagues [57] demonstrated that immature blood cells reprogram more efficiently than their differentiated progeny. These analyses may assist in the selection of suitable targets for the efficient generation of iPSCs.

Alternatively, small molecules that enhance reprogramming efficiency or even substitute for a reprogramming factor have been identified. Some of these compounds induce epigenetic changes by inhibiting the activity of chromatin remodeling factors. In the presence of the DNA methyltransferase inhibitor $5^{\prime}$-azacytidine $\left(5^{\prime}\right.$-azaC) or the histone deacetylase inhibitor VPA, the efficiency of reprogramming can be enhanced by approximately 10-fold and 100-fold, respectively [58]. Furthermore, VPA is able to compensate for c-Myc and Klf4 during conversion of human fibroblasts to iPSCs [59]. Likewise, the G9a histone methyltransferase inhibitor BIX-01294, together with BayK8644, an L-type calcium channel agonist, allows reprogramming of mouse embryonic fibroblasts transduced with Oct4 and Klf4 only [60]. Among the compounds that target signal transduction pathways, inhibitors of transforming growth factor-beta signaling have been shown to increase reprogramming efficiency and substitute for Sox2 and c-Myc [61,62]. Also, the kinase inhibitor kenpaullone was found to replace Klf4 [63], although the underlying mechanism is unknown at present. Finally, a recent report demonstrates that vitamin $\mathrm{C}$ improves the generation of mouse iPSCs and hiPSCs [64], in part by alleviating cell senescence through p53 repression and probably by acting as an agonist of the hypoxia-inducible factor pathway. These results are in agreement with the recent finding that 
hypoxic conditions also improve iPSC production [65]. Of note, many of these molecules have pleiotropic effects that could result in transient or permanent epigenetic or genetic alterations, hindering the use of chemically induced iPSCs for therapeutic purposes.

\section{Conclusions}

Reprogramming with defined transcription factors provides a simple way of producing customized pluripotent stem cells with enormous therapeutic potential. Although viral transduction of the Yamanaka factors remains the most common strategy for producing iPSCs, significant progress has been made in improving the efficiency and safety of the technique. Excisable vectors may prove suitable for most applications, and methods that rely on non-integrative vectors or protein delivery might become routine once their efficiency is enhanced. The use of high-throughput screening technologies to identify small molecules that modulate the expression and/or activity of regulators of pluripotency in somatic cells could potentially allow reprogramming by purely chemical means. Whether the choice of the donor cell and reprogramming method eventually have an effect on the ability of iPSCs to differentiate into functional cell types will require additional investigation. Given the rapid pace of the field, further optimization of the protocols coupled with a thorough analysis of the iPSC lines generated will facilitate the clinical translation of this technology.

\section{Abbreviations}

ESC, embryonic stem cell; hiPSC, human induced pluripotent stem cell; iPSC, induced pluripotent stem cell; IRES, internal ribosome entry site; LTR, long terminal repeat; $\mathrm{PB}$, piggyBac; $\mathrm{p}$-hiPSC, protein human induced pluripotent stem cell; STEMCCA, Stem Cell Cassette; VPA, valproic acid.

\section{Competing interests}

Boston University (Boston, MA, USA) has filed a STEMCCA vector patent, which is licensed to Millipore Corporation (Billerica, MA, USA). However according to Boston University competing interests policies the authors do not have a competing interest.

\section{Acknowledgments}

We are grateful to Darrell Kotton for critical reading of the manuscript. We apologize to those investigators whose work could not be cited because of space constraints.

Published: 10 August 2010

\section{References}

1. Jaenisch R, Young R: Stem cells, the molecular circuitry of pluripotency and nuclear reprogramming. Cell 2008, 132:567-582.

2. Takahashi K, Yamanaka S: Induction of pluripotent stem cells from mouse embryonic and adult fibroblast cultures by defined factors. Cell 2006, 126:663-676.

3. Hochedlinger K, Plath K: Epigenetic reprogramming and induced pluripotency. Development 2009, 136:509-523.

4. Park IH, Zhao R, West JA, Yabuuchi A, Huo H, Ince TA, Lerou PH, Lensch MW, Daley GQ: Reprogramming of human somatic cells to pluripotency with defined factors. Nature 2008, 451:141-146.

5. Takahashi K, Tanabe K, Ohnuki M, Narita M, Ichisaka T, Tomoda K, Yamanaka S: Induction of pluripotent stem cells from adult human fibroblasts by defined factors. Cell 2007, 131:861-872.
6. Yu J, Vodyanik MA, Smuga-Otto K, Antosiewicz-Bourget J, Frane JL, Tian S, Nie J, Jonsdottir GA, Ruotti V, Stewart R, Slukvin, II, Thomson JA: Induced pluripotent stem cell lines derived from human somatic cells. Science 2007, 318:1917-1920.

7. Lowry WE, Richter L, Yachechko R, Pyle AD, Tchieu J, Sridharan R, Clark AT, Plath K: Generation of human induced pluripotent stem cells from dermal fibroblasts. Proc Natl Acad Sci U S A 2008, 105:2883-2888.

8. Aasen T, Raya A, Barrero MJ, Garreta E, Consiglio A, Gonzalez F, Vassena R, Bilic J, Pekarik V, Tiscornia G, Edel M, Boue S, Izpisua Belmonte JC: Efficient and rapid generation of induced pluripotent stem cells from human keratinocytes. Nat Biotechno/ 2008, 26:1276-1284.

9. Yamanaka S: A fresh look at iPS cells. Cell 2009, 137:13-17.

10. Hanna J, Wernig M, Markoulaki S, Sun CW, Meissner A, Cassady JP, Beard C, BrambrinkT, Wu LC, Townes TM, Jaenisch R: Treatment of sickle cell anemia mouse model with iPS cells generated from autologous skin. Science 2007, 318:1920-1923.

11. Wernig M, Zhao JP, Pruszak J, Hedlund E, Fu D, Soldner F, Broccoli V, Constantine-Paton M, Isacson O, Jaenisch R: Neurons derived from reprogrammed fibroblasts functionally integrate into the fetal brain and improve symptoms of rats with Parkinson's disease. Proc Natl Acad Sci U S A 2008, 105:5856-5861.

12. Xu D, Alipio Z, Fink LM, Adcock DM, Yang J, Ward DC, Ma Y: Phenotypic correction of murine hemophilia A using an iPS cell-based therapy. Proc Natl Acad Sci U S A 2009, 106:808-813.

13. Okita K, Ichisaka T, Yamanaka S: Generation of germline-competent induced pluripotent stem cells. Nature 2007, 448:313-317.

14. Wernig M, Meissner A, Foreman R, BrambrinkT, Ku M, Hochedlinger K, Bernstein $B E$, Jaenisch R: In vitro reprogramming of fibroblasts into a pluripotent ES-cell-like state. Nature 2007, 448:318-324.

15. Maherali N, Sridharan R, Xie W, Utikal J, Eminli S, Arnold K, Stadtfeld M, Yachechko R, Tchieu J, Jaenisch R, Plath K, Hochedlinger K: Directly reprogrammed fibroblasts show global epigenetic remodeling and widespread tissue contribution. Cell Stem Cell 2007, 1:55-70.

16. Meissner A, Wernig M, Jaenisch R: Direct reprogramming of genetically unmodified fibroblasts into pluripotent stem cells. Nat Biotechno/ 2007, 25:1177-1181

17. Park IH, Arora N, Huo H, Maherali N, Ahfeldt T, Shimamura A, Lensch MW, Cowan C, Hochedlinger K, Daley GQ: Disease-specific induced pluripotent stem cells. Cell 2008, 134:877-886.

18. Dimos JT, Rodolfa KT, Niakan KK, Weisenthal LM, Mitsumoto H, Chung W, Croft GF, Saphier G, Leibel R, Goland R, Wichterle H, Henderson CE, Eggan K: Induced pluripotent stem cells generated from patients with ALS can be differentiated into motor neurons. Science 2008, 321:1218-1221.

19. Maherali N, Ahfeldt T, Rigamonti A, Utikal J, Cowan C, Hochedlinger K: A high-efficiency system for the generation and study of human induced pluripotent stem cells. Cell Stem Cell 2008, 3:340-345.

20. Sun N, Panetta NJ, Gupta DM, Wilson KD, Lee A, Jia F, Hu S, Cherry AM, Robbins RC, Longaker MT, Wu JC: Feeder-free derivation of induced pluripotent stem cells from adult human adipose stem cells. Proc Natl Acad SciUSA 2009, 106:15720-15725

21. Wu X, Li Y, Crise B, Burgess SM: Transcription start regions in the human genome are favored targets for MLV integration. Science 2003, 300:1749-1751.

22. Hotta A, Ellis J: Retroviral vector silencing during iPS cell induction: an epigenetic beacon that signals distinct pluripotent states. J Cell Biochem 2008, 105:940-948

23. Soldner F, Hockemeyer D, Beard C, Gao Q, Bell GW, Cook EG, Hargus G, Blak A, Cooper O, Mitalipova M, Isacson O, Jaenisch R: Parkinson's disease patientderived induced pluripotent stem cells free of viral reprogramming factors. Cell 2009, 136:964-977.

24. Sommer CA, Sommer AG, Longmire TA, Christodoulou C, Thomas DD, Gostissa M, Alt FW, Murphy GJ, Kotton DN, Mostoslavsky G: Excision of reprogramming transgenes improves the differentiation potential of iPS cells generated with a single excisable vector. Stem Cells 2010, 28:64-74.

25. Sommer CA, Stadtfeld M, Murphy GJ, Hochedlinger K, Kotton DN, Mostoslavsky G: Induced pluripotent stem cell generation using a single lentiviral stem cell cassette. Stem Cells 2009, 27:543-549.

26. Carey BW, Markoulaki S, Hanna J, Saha K, Gao Q, Mitalipova M, Jaenisch R: Reprogramming of murine and human somatic cells using a single polycistronic vector. Proc Natl Acad Sci U S A 2009, 106:157-162.

27. Chang CW, Lai YS, Pawlik KM, Liu K, Sun CW, Li C, Schoeb TR, Townes TM: 
Polycistronic lentiviral vector for "hit and run" reprogramming of adult skin fibroblasts to induced pluripotent stem cells. Stem Cells 2009, 27:1042-1049.

28. Wang W, Lin C, Lu D, Ning Z, Cox T, Melvin D, Wang X, Bradley A, Liu P: Chromosomal transposition of PiggyBac in mouse embryonic stem cells. Proc Natl Acad Sci U S A 2008, 105:9290-9295.

29. Woltjen K, Michael IP, Mohseni P, Desai R, Mileikovsky M, Hamalainen R, Cowling R, Wang W, Liu P, Gertsenstein M, Kaji K, Sung HK, Nagy A: piggyBac transposition reprograms fibroblasts to induced pluripotent stem cells. Nature 2009, 458:766-770.

30. Yusa K, Rad R, Takeda J, Bradley A: Generation of transgene-free induced pluripotent mouse stem cells by the piggyBac transposon. Nat Methods 2009, 6:363-369.

31. Kaji K, Norrby K, Paca A, Mileikovsky M, Mohseni P, Woltjen K: Virus-free induction of pluripotency and subsequent excision of reprogramming factors. Nature 2009, 458:771-775.

32. Geurts AM, Collier LS, Geurts JL, Oseth LL, Bell ML, Mu D, Lucito R, Godbout SA, Green LE, Lowe SW, Hirsch BA, Leinwand LA, Largaespada DA: Gene mutations and genomic rearrangements in the mouse as a result of transposon mobilization from chromosomal concatemers. PLoS Genet 2006, 2:e156.

33. Stadtfeld M, Maherali N, Breault DT, Hochedlinger K: Defining molecular cornerstones during fibroblast to iPS cell reprogramming in mouse. Cell Stem Cell 2008, 2:230-240

34. Brambrink T, Foreman R, Welstead GG, Lengner CJ, Wernig M, Suh $H$, Jaenisch $R$ : Sequential expression of pluripotency markers during direct reprogramming of mouse somatic cells. Cell Stem Cell 2008, 2:151-159.

35. Okita K, Nakagawa M, Hyenjong H, Ichisaka T, Yamanaka S: Generation of mouse induced pluripotent stem cells without viral vectors. Science 2008, 322:949-953.

36. Gonzalez F, Barragan Monasterio M, Tiscornia G, Montserrat Pulido N, Vassena R, Batlle Morera L, Rodriguez Piza I, Izpisua Belmonte JC: Generation of mouse-induced pluripotent stem cells by transient expression of a single nonviral polycistronic vector. Proc Nat/ Acad Sci U S A 2009, 106:8918-8922.

37. Stadtfeld M, Nagaya M, Utikal J, Weir G, Hochedlinger K: Induced pluripotent stem cells generated without viral integration. Science 2008, 322:945-949.

38. Jia F, Wilson KD, Sun N, Gupta DM, Huang M, Li Z, Panetta NJ, Chen ZY Robbins RC, Kay MA, Longaker MT, Wu JC: A nonviral minicircle vector for deriving human iPS cells. Nat Methods 2010, 7:197-199.

39. Fusaki N, Ban H, Nishiyama A, Saeki K, Hasegawa M: Efficient induction of transgene-free human pluripotent stem cells using a vector based on Sendai virus, an RNA virus that does not integrate into the host genome. Proc Jpn Acad Ser B Phys Biol Sci 2009, 85:348-362.

40. Yu J, Hu K, Smuga-Otto K, Tian S, Stewart R, Slukvin, II, Thomson JA: Human induced pluripotent stem cells free of vector and transgene sequences. Science 2009, 324:797-801.

41. Zhou H, Wu S, Joo JY, Zhu S, Han DW, Lin T, Trauger S, Bien G, Yao S, Zhu Y, Siuzdak G, Scholer HR, Duan L, Ding S: Generation of induced pluripotent stem cells using recombinant proteins. Cell Stem Cell 2009, 4:381-384.

42. Kim D, Kim CH, Moon Jl, Chung YG, Chang MY, Han BS, Ko S, Yang E, Cha KY, Lanza R, Kim KS: Generation of human induced pluripotent stem cells by direct delivery of reprogramming proteins. Cell Stem Cell 2009, 4:472-476.

43. Cho HJ, Lee CS, Kwon YW, Paek JS, Lee SH, Hur J, Lee EJ, Roh TY, Chu IS, Leem SH, Kim Y, Kang HJ, Park YB, Kim HS: Induction of pluripotent stem cells from adult somatic cells by protein-based reprogramming without genetic manipulation. Blood 2010 May 3. [Epub ahead of print]

44. Maherali N, Hochedlinger K: Guidelines and techniques for the generation of induced pluripotent stem cells. Cell Stem Cell 2008, 3:595-605.

45. Nakagawa M, Koyanagi M, Tanabe K, Takahashi K, Ichisaka T, Aoi T, Okita K, Mochiduki Y, Takizawa N, Yamanaka S: Generation of induced pluripotent stem cells without Myc from mouse and human fibroblasts. Nat Biotechnol 2008, 26:101-106.

46. Niwa H, Miyazaki J, Smith AG: Quantitative expression of Oct-3/4 defines differentiation, dedifferentiation or self-renewal of ES cells. Nat Genet 2000, 24:372-376.

47. Heng JC, Feng B, Han J, Jiang J, Kraus P, Ng JH, Orlov YL, Huss M, Yang L, Lufkin T, Lim B, Ng HH: The nuclear receptor Nr5a2 can replace Oct4 in the reprogramming of murine somatic cells to pluripotent cells. Cell Stem Cell 2010, 6:167-174.

48. Feng B, Jiang J, Kraus P, Ng JH, Heng JC, Chan YS, Yaw LP, Zhang W, Loh YH, Han J, Vega VB, Cacheux-Rataboul V, Lim B, Lufkin T, Ng HH: Reprogramming of fibroblasts into induced pluripotent stem cells with orphan nuclear receptor Esrrb. Nat Cell Biol 2009, 11:197-203.

49. Zhao $Y$, Yin $X$, Qin $H$, Zhu F, Liu H, Yang W, Zhang Q, Xiang C, Hou P, Song Z, Liu Y, Yong J, Zhang P, Cai J, Liu M, Li H, Li Y, Qu X, Cui K, Zhang W, Xiang T, Wu Y, Liu C, Yu C, Yuan K, Lou J, Ding M, Deng H: Two supporting factors greatly improve the efficiency of human iPSC generation. Cell Stem Cell 2008, 3:475-479.

50. Kim JB, Sebastiano V, Wu G, Arauzo-Bravo MJ, Sasse P, Gentile L, Ko K, Ruau D, Ehrich M, van den Boom D, Meyer J, Hubner K, Bernemann C, Ortmeier C, Zenke M, Fleischmann BK, Zaehres H, Scholer HR: Oct4-induced pluripotency in adult neural stem cells. Cell 2009, 136:411-419.

51. Kim JB, Zaehres H, Wu G, Gentile L, Ko K, Sebastiano V, Arauzo-Bravo MJ, Ruau D, Han DW, Zenke M, Scholer HR: Pluripotent stem cells induced from adult neural stem cells by reprogramming with two factors. Nature 2008, 454:646-650.

52. Aoi T, Yae K, Nakagawa M, Ichisaka T, Okita K, Takahashi K, Chiba T, Yamanaka $\mathrm{S}$ : Generation of pluripotent stem cells from adult mouse liver and stomach cells. Science 2008, 321:699-702.

53. Hanna J, Markoulaki S, Schorderet P, Carey BW, Beard C, Wernig M, Creyghton MP, Steine EJ, Cassady JP, Foreman R, Lengner CJ, Dausman JA, Jaenisch R: Direct reprogramming of terminally differentiated mature B lymphocytes to pluripotency. Cell 2008, 133:250-264.

54. Loh YH, Agarwal S, Park IH, Urbach A, Huo H, Heffner GC, Kim K, Miller JD, Ng K, Daley GQ: Generation of induced pluripotent stem cells from human blood. Blood 2009, 113:5476-5479.

55. Markoulaki S, Hanna J, Beard C, Carey BW, Cheng AW, Lengner CJ, Dausman JA, Fu D, Gao Q, Wu S, Cassady JP, Jaenisch R: Transgenic mice with defined combinations of drug-inducible reprogramming factors. Nat Biotechnol 2009, 27:169-171.

56. Stadtfeld M, Maherali N, Borkent M, Hochedlinger K: A reprogrammable mouse strain from gene-targeted embryonic stem cells. Nat Methods 2010 7:53-55

57. Eminli S, Foudi A, Stadtfeld M, Maherali N, Ahfeldt T, Mostoslavsky G, Hock H, Hochedlinger K: Differentiation stage determines potential of hematopoietic cells for reprogramming into induced pluripotent stem cells. Nat Genet 2009, 41:968-976.

58. Huangfu D, Maehr R, Guo W, Eijkelenboom A, Snitow M, Chen AE, Melton DA Induction of pluripotent stem cells by defined factors is greatly improved by small-molecule compounds. Nat Biotechnol 2008, 26:795-797.

59. Huangfu D, Osafune K, Maehr R, Guo W, Eijkelenboom A, Chen S, Muhlestein W, Melton DA: Induction of pluripotent stem cells from primary human fibroblasts with only Oct4 and Sox2. Nat Biotechnol 2008, 26:1269-1275.

60. Shi Y, Desponts C, Do JT, Hahm HS, Scholer HR, Ding S: Induction of pluripotent stem cells from mouse embryonic fibroblasts by Oct4 and Klf4 with small-molecule compounds. Cell Stem Cell 2008, 3:568-574.

61. Maherali N, Hochedlinger K: Tgfbeta signal inhibition cooperates in the induction of iPSCs and replaces Sox2 and cMyc. Curr Bio/ 2009, 19:1718-1723.

62. Ichida JK, Blanchard J, Lam K, Son EY, Chung JE, Egli D, Loh KM, Carter AC, Di Giorgio FP, Koszka K, Huangfu D, Akutsu H, Liu DR, Rubin LL, Eggan K: A smallmolecule inhibitor of tgf-Beta signaling replaces sox 2 in reprogramming by inducing nanog. Cell Stem Cell 2009, 5:491-503.

63. Lyssiotis CA, Foreman RK, Staerk J, Garcia M, Mathur D, Markoulaki S, Hanna J, Lairson LL, Charette BD, Bouchez LC, Bollong M, Kunick C, Brinker A, Cho CY, Schultz PG, Jaenisch R: Reprogramming of murine fibroblasts to induced pluripotent stem cells with chemical complementation of Klf4. Proc Natl Acad SciU S A 2009, 106:8912-8917.

64. Esteban MA, Wang T, Qin B, Yang J, Qin D, Cai J, Li W, Weng Z, Chen J, Ni S, Chen K, Li Y, Liu X, Xu J, Zhang S, Li F, He W, Labuda K, Song Y, Peterbauer A, Wolbank S, Redl H, Zhong M, Cai D, Zeng L, Pei D: Vitamin C enhances the generation of mouse and human induced pluripotent stem cells. Cell Stem Cell 2010, 6:71-79.

65. Yoshida Y, Takahashi K, Okita K, Ichisaka T, Yamanaka S: Hypoxia enhances the generation of induced pluripotent stem cells. Cell Stem Cell 2009, 5:237-241.

\section{doi:10.1186/scrt26}

Cite this article as: Sommer CA, Mostoslavsky G: Experimental approaches for the generation of induced pluripotent stem cells. Stem Cell Research \&

Therapy 2010, 1:26. 